\title{
"Answer to: Diabetes distress and peripheral neuropathy are associated with medication non-adherence in individuals with type 2 diabetes in primary care"-authors' reply
}

\author{
Zhi Peng Zhang ${ }^{1} \cdot$ M. Premikha ${ }^{2} \cdot$ Miyang Luo $^{3} \cdot$ Kavita Venkataraman ${ }^{3}$
}

Received: 27 April 2021 / Accepted: 3 May 2021 / Published online: 24 May 2021

(c) Springer-Verlag Italia S.r.l., part of Springer Nature 2021

To,

Dr Massimo Porta,

Editor-in-Chief,

Acta Diabetologica.

We thank Lima et al. [1] for their interest in and appreciation of the work presented in our research article. We concur that non-adherence is an important determinant of outcomes in people with diabetes. Indeed, this is why we chose to investigate medication and treatment non-adherence and their correlates in our primary care population with diabetes.

Lima et al. raise the important issue of research on strategies to improve adherence to medication and appointments among people with disease in their letter. We agree that adherence to medical advice is a modifiable determinant of outcomes, and therefore, strategies to improve adherence are of great importance. Interventions such as phone coaching, involvement of pharmacist or other care manager, psychological support and patient education have previously been shown to lead to improvement in medication adherence [2]. However, most studies have included small numbers of participants and have been of relatively short duration.

In our work, we have identified diabetes distress and presence of peripheral neuropathy as key correlates of medication non-adherence. We have also previously reported that people with diagnosed disease had poorer health-related quality of life [3]. These findings indicate that greater support from the

Managed by Massimo Porta.

This reply refers to the comment available online at https://doi.org/ 10.1007/s00592-021-01733-7.

Kavita Venkataraman

kavita_v@nus.edu.sg

National University Polyclinics, Singapore, Singapore

2 Ministry of Health Holdings Pte Ltd, Singapore, Singapore

3 Saw Swee Hock School of Public Health, National University of Singapore, Singapore, Singapore health system and person-centred care may be potentially beneficial strategies to help people cope with their disease better and improve their adherence. In Singapore, there are attempts over the last few years to redesign care models in polyclinics. These new changes aim to improve the longitudinal relationship between patients and their healthcare teams and empower patients for self-care. Hopefully, over time this will improve patients' adherence to both treatment and appointments. These and other approaches should be evaluated over a longer time horizon to fully assess their impact on adherence.

We strongly support greater research in this area and the development and evaluation of new strategies that can inform clinical practice and care for people living with diabetes. At the same time, we would like to underscore the value of early identification of disease [4] in order to reduce risk of complications and poor outcomes, given that half of those with diabetes globally remain undiagnosed [5].

\section{References}

1. Zhang ZP, Premikha M, Luo M, Venkataraman K (2021) Diabetes distress and peripheral neuropathy are associated with medication nonadherence in individuals with type 2 diabetes in primary care. Acta Diabetol 58(3):309-317

2. Capoccia K, Odegard PS, Letassy N (2016) Medication adherence with diabetes medication: a systematic review of the literature. Diabetes Educ 42(1):34-71

3. Venkataraman K, Khoo C, Wee HL, Tan CS, Ma S, Heng D et al (2014) Associations between disease awareness and health-related quality of life in a multi-ethnic Asian population. PLoS ONE 9(11):e113802

4. Venkataraman K, Wee HL, Ng SHX, Rebello S, Tai ES, Lee J et al (2016) Determinants of individuals' participation in integrated chronic disease screening in Singapore. J Epidemiol Community Health 70(12):1242-1250

5. IDF (2019) IDF Diabetes Atlas Brussels, Belgium: International Diabetes Federation

Publisher's Note Springer Nature remains neutral with regard to jurisdictional claims in published maps and institutional affiliations. 